\title{
The rejection of anionic dyes and salt from water solutions using a polypropylene microfilter
}

\author{
John J. Porter ${ }^{a^{*}}$, Arlindo C. Gomes ${ }^{b}$ \\ ${ }^{a}$ School of Textile Fiber and Polymer Science, College of Engineering and Science, Clemson University, \\ Clemson, SC 29634, USA \\ Tel.+1 (864)656-5960;Tax+1 (864)656-5973; email:porter@mail.clemson.edu \\ ${ }^{b}$ Department of Chemistry, University of Da Beira Interior, Covilha, Portugal
}

Received 1 September 1999; accepted 1 December 1999

\begin{abstract}
Previous work reported by this laboratory showed that inorganic membranes such as stainless steel and ceramic microfilters were capable of rejecting anionic dyes and sodium nitrate from water solutions. It was of interest to see if this were possible with organic membranes such as propylene microfilters. Experimental data are presented showing that a polypropylene microfilter will reject both salt and Direct Red 2 from aqueous solutions when the conductivity of the solution is below $500 \mu$ Siemens. The use of microfiltration to remove color is an important phenomenon considering that microfiltration comprises the largest fraction of the total membrane production in the world and is now used commercially for tertiary biological wastewater treatment. The effect of $\mathrm{pH}$ and salt concentration on the filtration rate and color rejection is also presented.
\end{abstract}

Keywords: Organic membranes; Microfiltration; Tertiary treatment; Dye filtration

\section{Introduction}

The increase in the use of microfilters in recent years has been so significant that they now comprise the largest faction of total membrane production [1]. Not only are these filters able to remove suspended solids from aqueous solutions,

\footnotetext{
*Corresponding author.
}

but they also have been recently shown to be capable of removing soluble anionic dyes from aqueous solutions [2,3]. Data reported by this laboratory $[2,3]$ have shown that titania-coated stainless steel and ceramic microfilters are capable of rejecting Direct Red 2 and Acid Red 1 from deionized water. Since these experiments were performed with deionized and microfiltered water having a conductivity of less than $1 \mu$ Siemens, the ionic rejections could not be 
attributed to the presence of dynamically formed membranes produced during the course of the experiment. To see if the rejection mechanism were a characteristic of inorganic titania membranes, an organic polypropylene microfilter was selected for evaluation. The dyes used for this work are representative of the types of soluble dyes which would be present in many industrial waste streams and resistant to normal biological treatment processes.

The data describing the filtration characteristics of ceramic [2] and stainless steel tubular microfilters [3] were obtained on tubes coated with a fused asymmetric titanium dioxide layer having a nominal pore diameter of 0.2 microns. Microfilters such as these are generally described [4] as being able to separate suspended particulate with a particle diameter of greater than 0.1 microns from aqueous solutions. When they are used to remove suspended material from water, it is generally assumed that the filter will not remove salts. Because salt rejection was observed in the previous study [2,3], it was the objective of this research to investigate the filtration properties of a commercial organic polypropylene microfilter to see if similar rejections would occur with this organic membrane.

\section{Laboratory set-up}

All the laboratory tests were conducted on the pilot unit shown in Fig. 1. The system is constructed of 316 stainless steel tubes and fittings, except for the multi-stage pump impeller, which is fabricated from Dupont Delrin plastic with a temperature limit of $70^{\circ} \mathrm{C}$. The unit was fitted with temperature and pressure cut-off switches to protect the pump impeller and allow for more independent operation. A 115-L stainless steel, steam jacketed tank was used to supply feed water to the pilot unit.

The polypropylene module used was $30 \mathrm{~mm}$ in diameter and $700 \mathrm{~mm}$ in length and contained

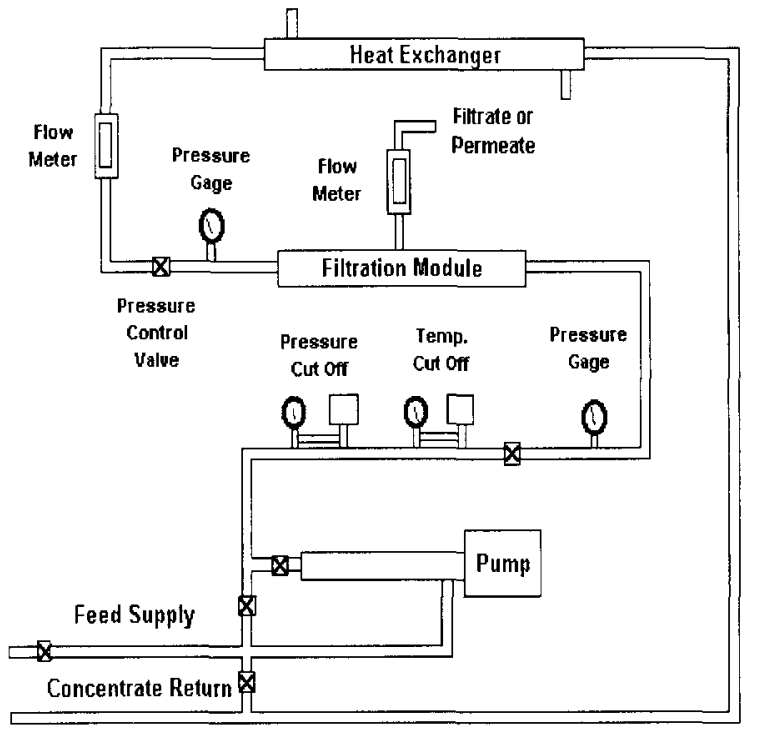

Fig. 1. Laboratory filtration system.

three channels, $5.5 \mathrm{~mm}$ in diameter. The module was supplied by Microdyne Technologies, Inc., (Raleigh, NC, US) and had a total surface area of $362.9 \mathrm{~cm}^{2}$ and a membrane nominal pore diameter of 0.2 microns. It could be operated at temperatures below $65^{\circ} \mathrm{C}$ and could withstand $\mathrm{pHs}$ of 1-14. The pore size was obtained from the module manufacturer, Akzo Nobel Faser A.G. (Wuppertal, Germany). The tubes were cleaned using a laboratory detergent solution in deionized water before use. Analytical measurements for conductivity were made with a Myron L DS conductance meter standardized against gravimetrically prepared sodium nitrate solutions), a Milton Roy Spectronic 20D colorimeter, and an Orion Model 250A laboratory $\mathrm{pH}$ meter. The $\mathrm{pHs}$ of all solutions were adjusted with reagent grade $10 \%$ nitric acid and $10 \%$ sodium hydroxide. Direct Red 2 was chosen for the study because of its use in previous work [2], its stability to hot water and its extensive use in the textile industry. The dye was crystallized from water and acetone using a published procedure [5] to obtain relatively pure dye, free of commercial additives. 
The laboratory detergent used for cleaning the module and filtration system was obtained from Baxter Scientific and labeled as micro concentrated cleaning solution. Chemical constituents in the cleaner were glycine $\mathrm{N}, \mathrm{N}^{\prime}-1,2$-ethanediylbis (N-carboxymethyl)-tetrasodium salt; benzene sulfonic acid, dimethylammonium salt; benzene sulfonic acid, dodecyl-, cpd. with $2,2^{\prime}, 2^{\prime \prime}$ nitrilotris-ethanol; poly(oxy-1, 2-ethaanediyl), alpha-(4-nonyl(phenyl)-omega-hydroxy, branched.

Flow rates in the tube were maintained at $4.3 \mathrm{~m} / \mathrm{s}$ to provide turbulence (Reynold's numbers $>30,000)$ and to minimize concentration polarization and surface fouling. Conductivity rejections were determined using Eq. (1).

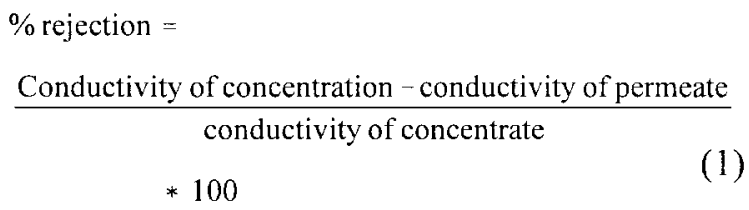

It is possible to get a reasonable estimate of the total electrolyte concentration (for a simple monovalent salt) in PPM by multiplying the conductance by 0.6 [2]. In this study the additional electrolyte, other than that contributed by the dyes, would be sodium nitrate, nitric acid, sodium hydroxide.

\section{Results and discussion}

The rejection of simple salts and ionic dyes by 0.2 micron ceramic and stainless steel microfilters was recently reported $[2,3]$ by this laboratory. Both inorganic microfilters were coated with a fused layer of titanium dioxide and are generally used to remove small particulate from aqueous solutions. Neither of the microfilters is supposed to be able to reject soluble salts and ionic dyes from aqueous solutions. Because of the unusual rejection properties found with the inorganic membranes, it was desirable to conduct studies with an organic microfilter to see how it would perform under similar conditions. The organic microfilter selected for evaluation was a polypropylene tubular module supplied by Microdyne Technologies, Inc. (Raleigh, NC, US) and should be the least polar of any membrane material other than fluorocarbon membranes.

An experiment was performed in the laboratory to evaluate the effect of temperature on the filtration rate and conductivity rejection of the polypropylene membrane. The results are shown in Fig. 2 with the data previously obtained with the stainless steel and ceramic tubes. The curve obtained with the polypropylene microfitler is linear and does not have the same curvature as the data shown for the two inorganic membranes. The decrease in viscosity of the aqueous solution with increasing temperature accounts for the shape of the curves for the two inorganic membranes. Evidently the cylindrical shape of the tubular polypropylene membrane restricts the thermoplastic organic membrane surface from expanding and the pores actually decrease in diameter as the polypropylene expands with increasing temperature. The two inorganic membranes are much more rigid than the polypropylene and should show no significant expansion over the narrow temperature range used. Since the fluid in all cases was deionized water, the relative shape of the curves should be similar if the polypropylene pores do not change with increasing temperature. It is most interesting that the conductivity rejections obtained with the three membranes is similar considering that they represent two entirely different chemical compositions. In the cases presented the rejection is more a function of the solution and the pore size than the membrane composition.

A second experiment, shown in Fig. 3, was conducted where the $\mathrm{pH}$ was changed during the filtration to see the effect of $\mathrm{pH}$ on the filtration characteristics of the membrane. The filtration rate remained relatively constant or increased 


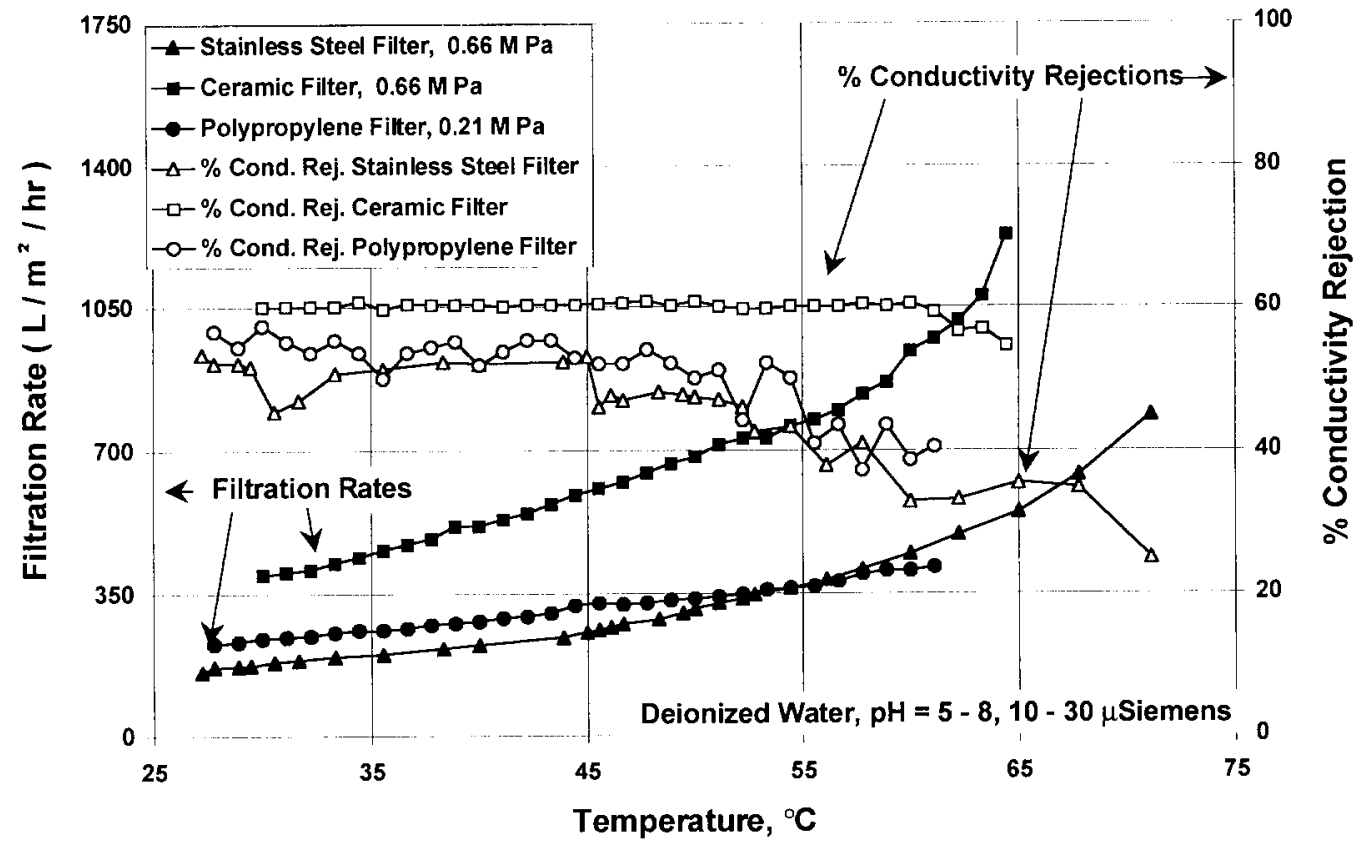

Fig. 2. Filtration rate for deionized water using stainless steel, ceramic and polypropylene microfilters at a flow velocity of $4.3 \mathrm{~m} / \mathrm{s}$.

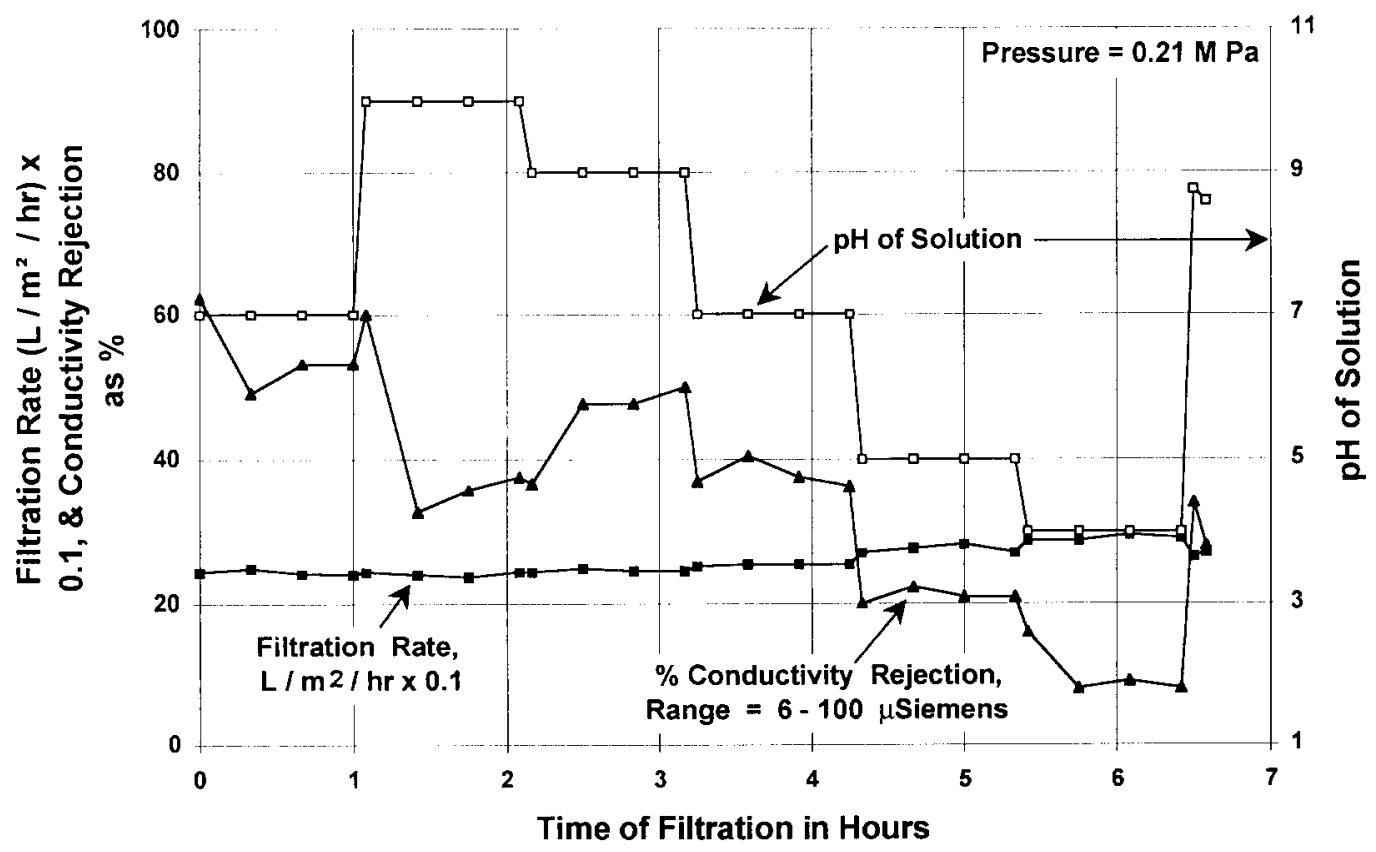

Fig. 3. Effect of $\mathrm{pH}$ on filtration rate for deionized water using a polypropylene microfilter at a flow velocity of $4.3 \mathrm{~m} / \mathrm{s}$ at $30^{\circ} \mathrm{C}$. 
slightly over the $\mathrm{pH}$ range of 4-10 used for the experiment. As was found with the previous work $[2,3]$, the conductivity rejection averaged $35 \%$ and decreased as the $\mathrm{pH}$ was lowered to four. At the end of the experiment the conductivity rejection increased when the $\mathrm{pH}$ was adjusted to 7.5. The filtration rates for the polypropylene module were significantly higher than the inorganic membranes considering the fact that the polypropylene microfilter was operated at a pressure of two atmospheres and the inorganic membranes $[2,3]$ were operated at $6.5 \mathrm{~atm}$ pressure.

\subsection{Results with Direct Red 2 dye}

To investigate the membrane filtration of larger ions Direct Red 2 was selected because it was used for the previous studies $[2,3]$ and is<smiles>Cc1cc(-c2ccc(N=Nc3cc(O[Na])c4ccccc4c3N)c(C)c2)ccc1N=Nc1cc(O[Na])c2ccccc2c1N</smiles>

Fig. 4. Structure of Direct Red 2 dye, C.I. 23500.

widely used by the textile and paper industry. The structure for the dye is shown in Fig. 4. It is resistant to degradation at the $\mathrm{pHs}$ and temperatures used $\left(30-60^{\circ} \mathrm{C}\right)$ for the study. Data were taken a $\mathrm{pH}$ from 10 to 4 to show the effect of $\mathrm{pH}$ on the filtration properties of the polypropylene microfilter (shown in Figs. 5-8). The average conductivity and dye rejection for each experiment is shown in Table 1 . The average rejections are lower than those obtained with the inorganic

Table 1

Performance of polypropylene, ceramic and stainless steel microfilters with deionized water containing Direct Red 2 dye at flow velocities of $4.3 \mathrm{~m} / \mathrm{s}$

\begin{tabular}{|c|c|c|c|c|c|}
\hline \multirow[t]{2}{*}{ Membrane } & \multirow[t]{2}{*}{ Temp., ${ }^{\circ} \mathrm{C}$} & \multirow[t]{2}{*}{ Permeate rate ${ }^{\mathrm{a}}, \mathrm{L} / \mathrm{m}^{2} / \mathrm{h}$} & \multicolumn{2}{|c|}{ Conductivity $^{\mathrm{a}}, \mu$ Siemens } & \multirow[t]{2}{*}{ Color ${ }^{\mathrm{a}}, \%$ rejection } \\
\hline & & & Concentrate & $\%$ rejection & \\
\hline $\begin{array}{l}\mathrm{TiO}_{2}+\text { stainless steel } \\
\text { - Surface: } 294 \mathrm{~cm}^{2} \\
\text { - Cross-sec: } 1.85 \mathrm{~cm}^{2} \\
\text { - Avg. press in tube, } 0.66 \mathrm{MPa}\end{array}$ & $\begin{array}{l}30 \\
45 \\
60\end{array}$ & $\begin{array}{l}129 \\
156 \\
180\end{array}$ & $\begin{array}{l}102 \\
266 \\
351\end{array}$ & $\begin{array}{l}61 \\
43 \\
41\end{array}$ & $\begin{array}{l}88 \\
84 \\
83\end{array}$ \\
\hline $\begin{array}{l}\mathrm{TiO}_{2}+\text { ceramic } \\
\text { - Surface: } 396 \mathrm{~cm}^{2} \\
\text { - Cross-sec: } 1.11 \mathrm{~cm}^{2} \\
\text { - Avg. press in tube, } 0.66 \mathrm{MPa}\end{array}$ & $\begin{array}{l}30 \\
45 \\
60\end{array}$ & $\begin{array}{l}435 \\
423 \\
605\end{array}$ & $\begin{array}{l}150 \\
178 \\
498\end{array}$ & $\begin{array}{l}54 \\
65 \\
42\end{array}$ & $\begin{array}{l}99 \\
96 \\
95\end{array}$ \\
\hline $\begin{array}{l}\text { Polypropylene } \\
\text { - Surface: } 363 \mathrm{~cm}^{2} \\
\text { - Cross-sec: } 0.713 \mathrm{~cm}^{2} \\
\text { - Avg. press in tube, } 0.21 \mathrm{MPa}\end{array}$ & $\begin{array}{l}30 \\
45 \\
45 \\
60\end{array}$ & $\begin{array}{l}331 \\
407 \\
399 \\
498\end{array}$ & $\begin{array}{r}58 \\
217 \\
4420 \\
330\end{array}$ & $\begin{array}{r}71 \\
7 \\
2 \\
5\end{array}$ & $\begin{array}{l}56 \\
44 \\
18 \\
43\end{array}$ \\
\hline
\end{tabular}

${ }^{\mathrm{a}}$ Most of these data represent the average of data taken during several runs as shown in Figs. 5-7. 


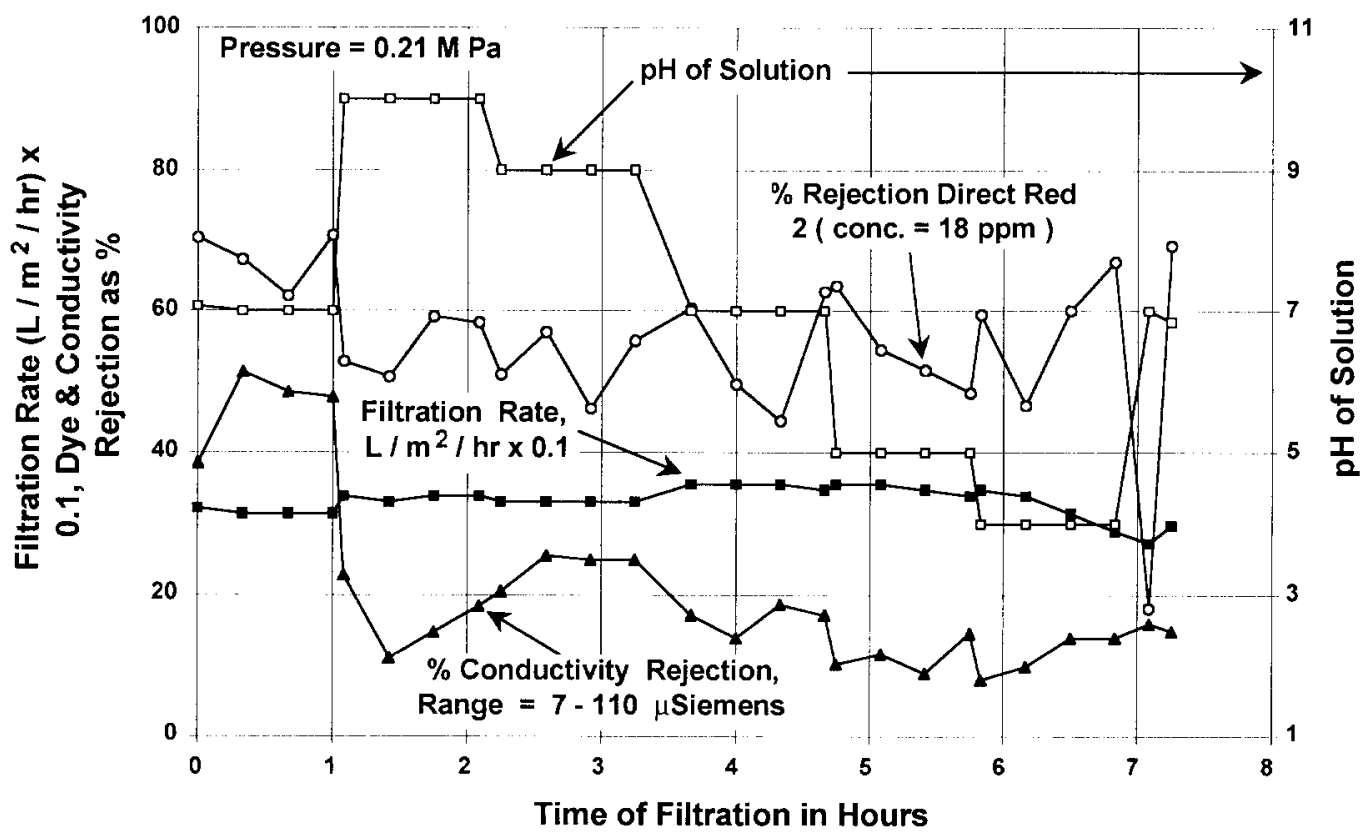

Fig. 5. Filtration rate for deionized water and Direct Red 2 using a polypropylene microfilter at a flow velocity of $4.3 \mathrm{~m} / \mathrm{s}$ at $30^{\circ} \mathrm{C}$.

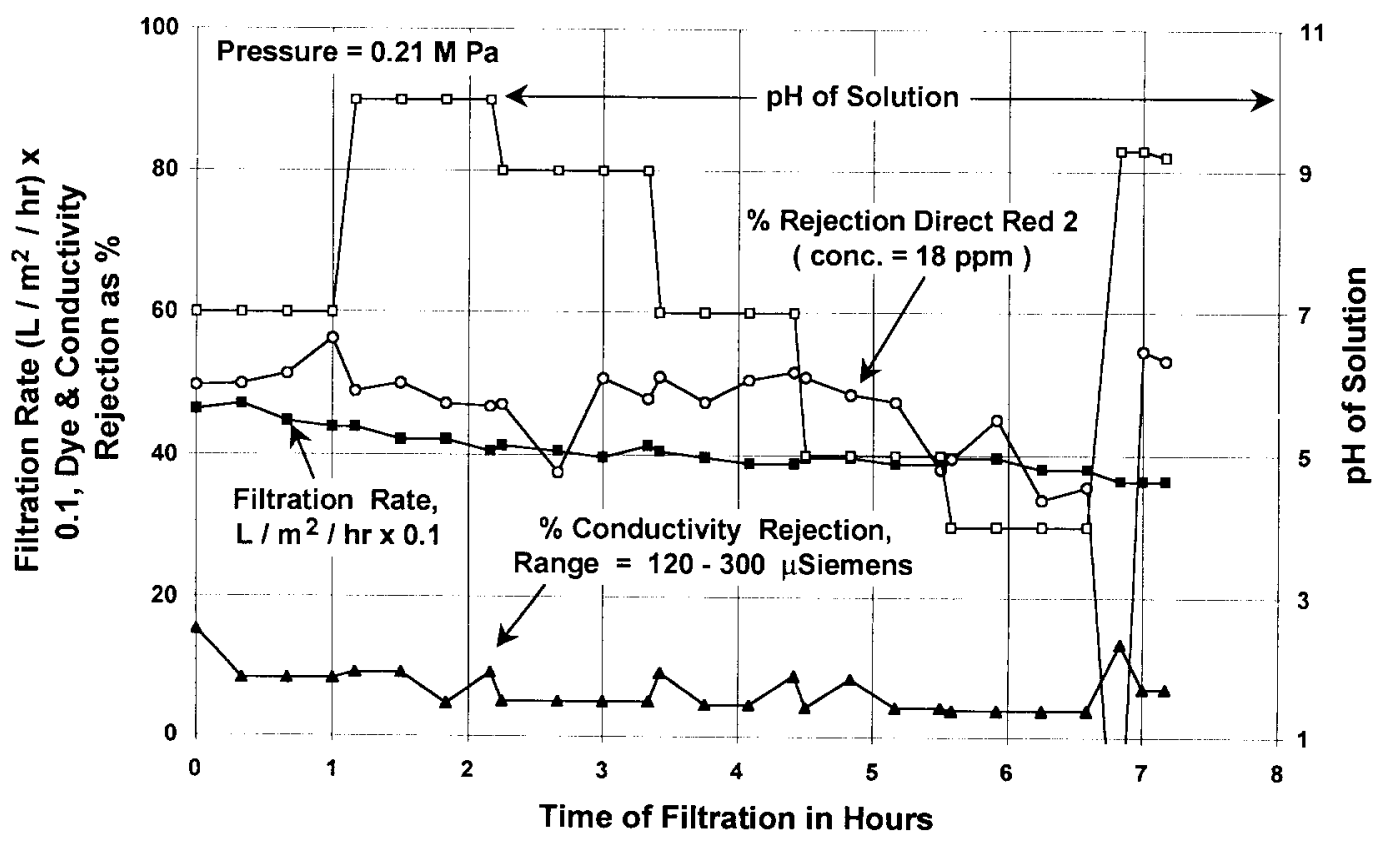

Fig. 6. Filtration rate for deionized water and Direct Red 2 using a polypropylene microfilter at a flow velocity of $4.3 \mathrm{~m} / \mathrm{s}$ at $45^{\circ} \mathrm{C}$. 


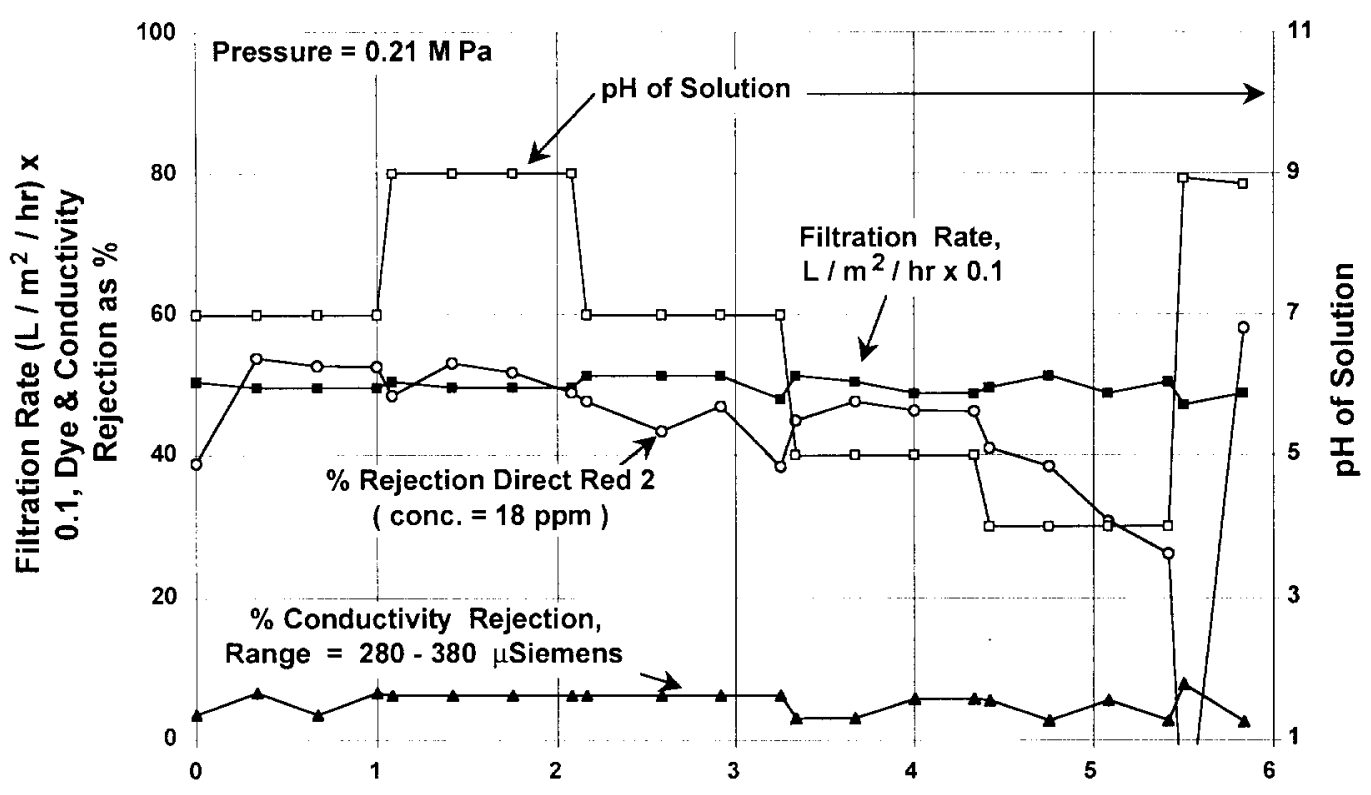

Time of Filtration in Hours

Fig. 7. Filtration rate for deionized water and Direct Red 2 using a polypropylene microfilter at a flow velocity of $4.3 \mathrm{~m} / \mathrm{s}$ at $60^{\circ} \mathrm{C}$.

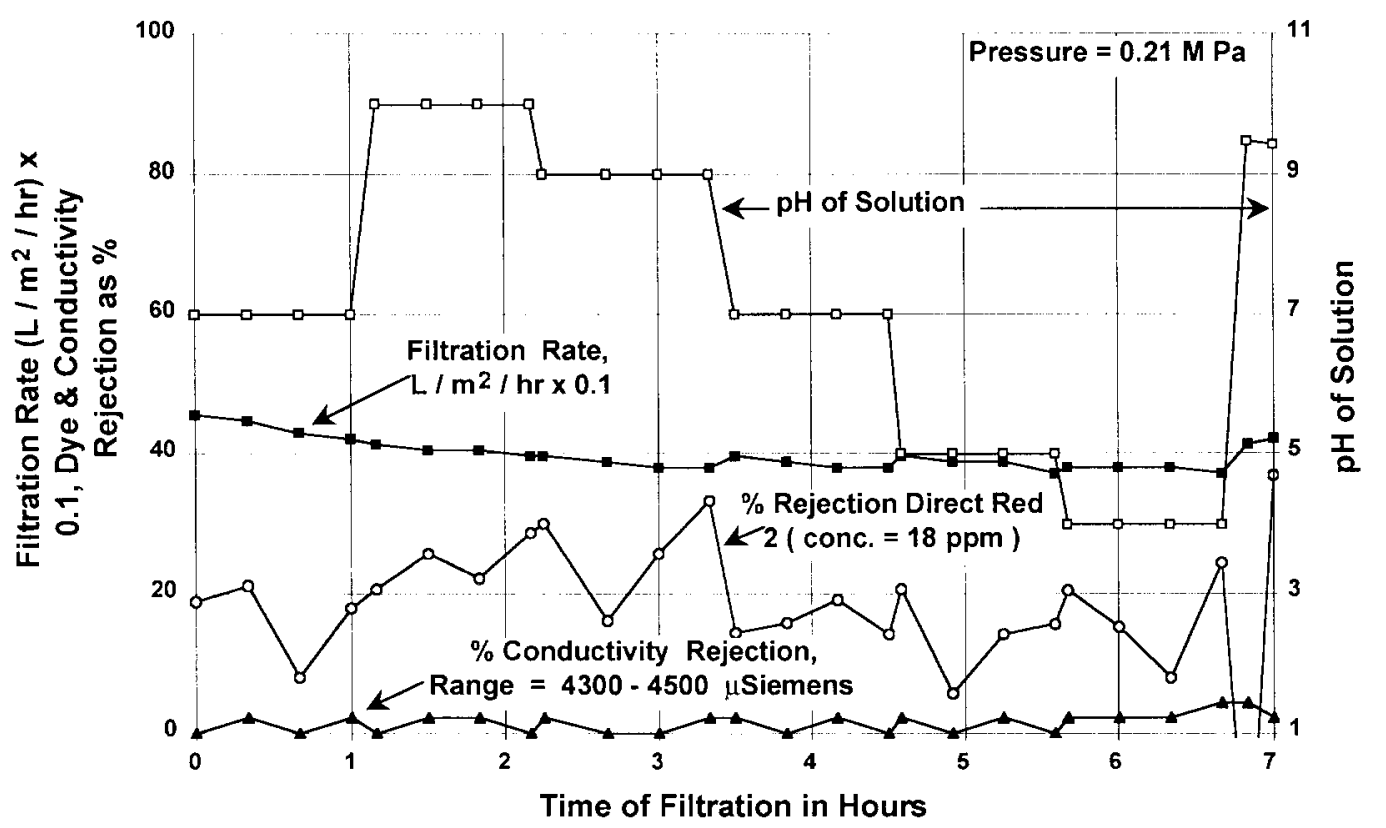

Fig. 8. Filtration rate for deionized water and Direct Red 2 at high conductivity using a polypropylene microfilter at a flow velocity of $4.3 \mathrm{~m} / \mathrm{s}$ at $45^{\circ} \mathrm{C}$. 
membranes [2,3], also shown in Table 1. At the three temperatures approximately $50 \%$ of the dye was rejected, which is very significant for a microfilter having pores $0.2 \mathrm{micron}$ in diameter.

The polypropylene membrane evidently has a slightly larger average pore diameter than the inorganic membranes. This would account for the larger filtration rates at the lower pressure. This would also account for the lower rejections obtained with the organic membrane. The fact that salt rejection did occur indicates that similar electrostatic forces were effecting the filtration of the polypropylene membrane that was found with the two inorganic microfilters.

It would be interesting to investigate the ionic dye rejection of microfilters having nominal pore diameters of 0.1 microns and smaller. It is logical to expect microfilters with smaller pores than those used for this study to reject dyes and salts better. Microfilters are now commercially available with a wide range of rejection properties. In many cases it may not be necessary to use a nanofilter to reject soluble ionic dyes. A microfilter may be used and give filtration rates that are much higher than those available with nanofiltration. The limitation of using microfilters for ionic dye removal is that less than $100 \%$ of the dye is rejected. In those applications where $>95 \%$ of the dye must be rejected, it will be necessary to use a membrane with smaller pores or nanofiltration. The limitation with using nanofiltration is that a much lower filtration rates will be obtained requiring more membrane surface and higher filtration pressures. Additional work using microfilters having nominal pore sizes smaller than 0.2 microns may provide a beneficial solution to this problem.

\subsection{Correlation with the Debye length}

One plausible explanation for the rejection of sodium and nitrate ions by a microfilter having a nominal pore diameter of $2000 \AA$ is the presence of an electrostatic field. The field can reach into the solution from the surface of the membrane to a distance of many angstroms and influence to passage of ions. In previous work with a ceramic membrane [2], it was possible to show that the relation between the percent conductivity rejection vs. the conductivity of the filtering solution was very similar to the Debye length and conductivity that exist between the ions in aqueous solutions. The correlation that was developed from the work with the ceramic membrane is shown in Eq. (2):

$$
\begin{aligned}
& \% \text { conductivity rejection }=980 \\
& *(\text { cond. of concentrate, } \mu \text { Siemens })^{-0.5}
\end{aligned}
$$

Israelachvili [6] developed an equation using Grahame's equation [7] to determine charge effects that reach up to $300 \AA$ into very dilute solutions. The equation is shown below as Eq. (3)

Debye length, namometers $=\frac{1}{\kappa}=3.04$

*(sodium nitrate, equiv./L) $)^{-0.5}$

where $1 / \kappa$ is the Debye length. This equation can be applied to solutions of $1: 1$ electrolytes where the surface potentials are below $25 \mathrm{mV}$. The surface potential was not measured, but sodium nitrate was a 1:1 electrolyte and accounted for at least $98 \%$ of the ions in solution for the data shown in Fig. 9. Since the conductivity of a sodium nitrate solution is essentially linear with the salt concentration, it is possible to substitute the conductivity into Eq. (3) in place of the sodium nitrate concentration to give Eq. (4):

Debye length, $\AA=1150$ *

(sodium nitrate conductivity, $\mu$ Siemens) $)^{-0.5}$

The only difference in Eq. (2) and Eq. (4) is the value of the constants 980 and 1150 . As sodium 


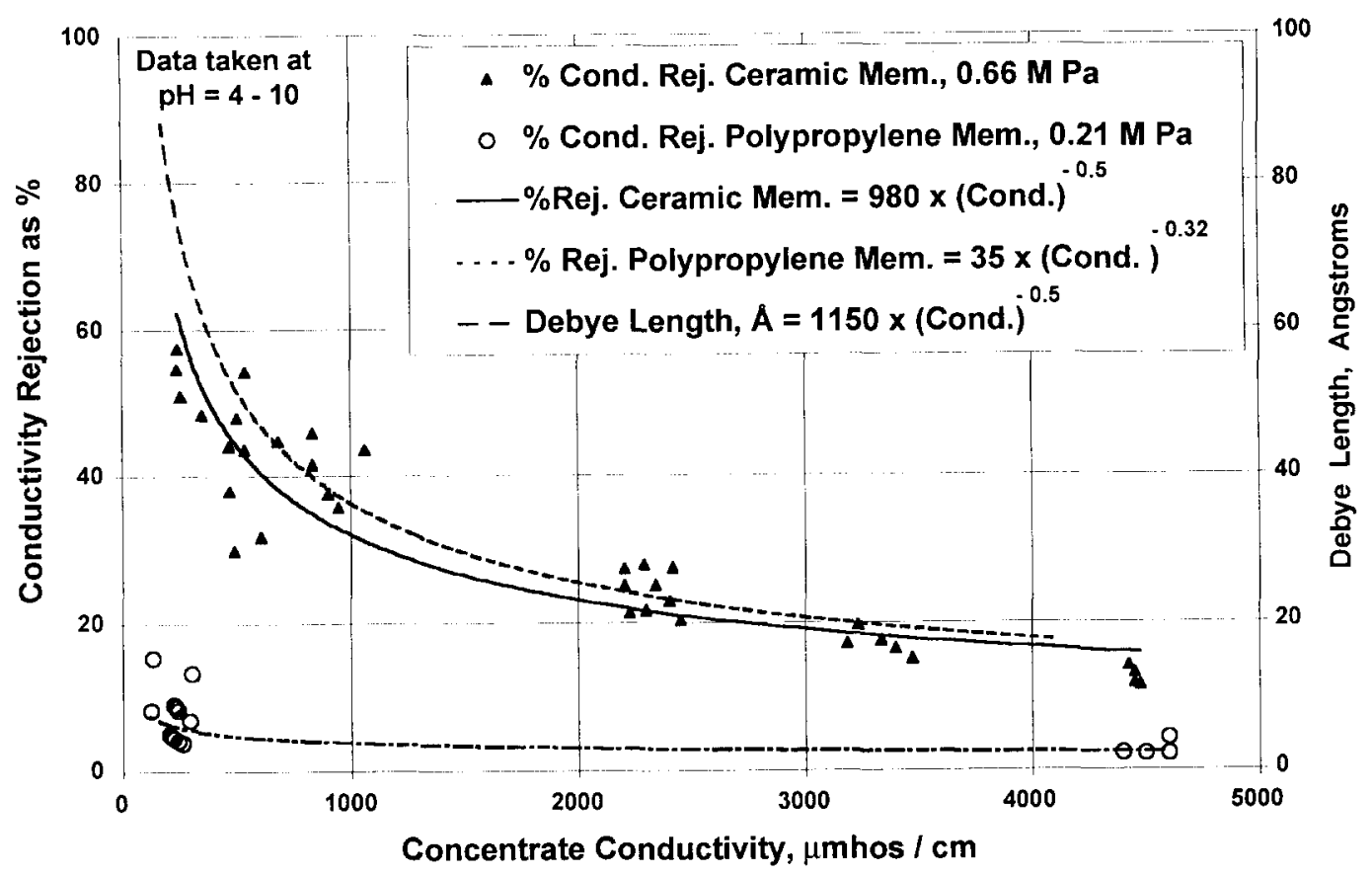

Fig. 9. Correlation of conductivity rejection with conductivity for poly propylene and ceramic microfilters at a flow velocity of $4.3 \mathrm{~m} / \mathrm{s}$ at $45^{\circ} \mathrm{C}$.

nitrate was used in our experiments [2] and Israelachvili's [7], the similar correlation of the data with the conductivity of the solution indicates that the same type of electrostatic forces are controlling both processes.

While the polypropylene membrane gave a much weaker field effect, as the curve in Fig. 9 shows, the electrostatic forces appear to influence the rejection in a similar manner. Another explanation for the smaller rejection of ions may be the presence of larger pores in the polypropylene membrane than the ceramic membrane, as proposed earlier to account for the higher filtration rates obtained with the organic membrane. This would explain the lack of correlation with Israelachvili's [7] equation. Considering that no rejection was expected with the organic polypropylene membrane, the results obtained were most interesting.
When the salt or electrolyte concentration is raised to give conductivity's of greater than $4000 \mu$ Siemens, the rejection approaches zero but is still measurable. This was also found with the stainless steel and ceramic microfilter which both showed higher rejections at high conductivity concentrations. The degree of fouling in all cases no doubt influences the results obtained. However, in all cases microfiltered and deionized water was used and the system cleaned frequently to eliminate and minimize this problem. The use of stainless steel for the fabrication of the laboratory system should minimize fouling. Rejections that can be expected in commercial applications that use normal tap water should be higher than those reported here, and for this reason it is important to collect data carefully before assuming that ionic dyes and salts are not rejected in commercial applications. 


\section{Conclusions}

Many times it is assumed that low molecular weight ions or even larger molecules will pass freely through microfilters similar to the ones used in the experiments reported in this paper. The data presented show that caution should be taken with the use of any microfilter. Careful analysis of the filtration data must be made before it is assumed that ions or molecules in the stream will freely pass through the microfilter. Trace contaminants would be sufficient to influence the passage of ions of low molecular weight. Good quality tap water and deionized water can produce similar results causing the microfilter to reject electrolytes after a few hours of operation. The time necessary to cause the filter to reject ions will depend on the construction materials used for the filtration system and the intrusion of trace particulate from any source. The filtering characteristics of relatively inert membranes, such as the polypropylene membrane used in this study, no doubt can change as they are used and repeatedly cleaned over time.

The important advantage of using microfiltration is that the membranes should have a much higher filtration rate per unit area and require much less membrane surface. Because of this the membrane cost may be much less in many applications. More work is needed with microfilters having lower nominal pore diameters than the microfilters used in this study, i.e., $<0.2$ microns. It should be possible to take advantage of the electrostatic properties of the membranes to separate many different ions. The chemically inert characteristics of the polypropylene membranes discussed in this paper are a decided advantage in most industrial applications.

\section{Acknowledgments}

The authors are indebted to Walter Pupa of Microdyne Technologies, Inc. (Raleigh, NC, US) for supplying the polypropylene module (Akzo Nobel Faser A.G.) used in this work and for providing helpful discussions during the course of the study. Funding for this work was received from the School of Textiles, Fiber and Polymer Science, Clemson University, and the Fundação para a Ciência e Tecnologia Praxis XXI, ref. 3/3.2/Papel/2328/95, University of Da Beira Interior, Covilha, Portugal.

\section{References}

[1] The Membrane Business - 10 Years Back, 10 Years Forward, Membrane Technology Separations Planning Conference, 1997, Newton, MA, USA.

[2] J.J. Porter and S. Zhuang, J. Membr. Sci., 110 (1996) 119.

[3] J.J. Porter and R.S. Porter, J. Membr. Sci., 101 (1995) 67.

[4] H. Winston, W.S. Sirkar and K.K. Sirkar, Membrane Handbook, Van Nostrand Reinhold, New York, 1992, p. 455.

[5] M.H. Hall and W.S. Perkins, Textile Res. J., 41 (1971) 923.

[6] D.C. Grahame, J. Chem. Physics, 21 (1953) 1054.

[7] J.N. Israelachvili, Intermolecular and Surface Forces, Academic Press, London, 1985, p. 180. 